\title{
Comparison between the Personality Dimensions of Delinquents and Non-Delinquents of Khyber Pukhtunkhwa (KPK), Pakistan
}

\author{
Sehrish Khan \\ Department of Humanities, Comsats Institute of Information and Technology, Abbottabad, Pakistan \\ Email: sehrishkhan@ciit.net.pk \\ Received February 2014
}

\begin{abstract}
This study was an attempt to find out the comparison between the personality dimensions of delinquents and non delinquents of Khyber Pukhtonkhwa (KPK). Eysenck personality Questionnaire (junior) (Urdu Version 2007) was administered on the sample of 400 (Delinquents $=200$, non-delinquents $=200$ ). Delinquents were the inmates in different jails of KPK while non-delinquents were the students of different colleges of KPK. It was hypothesized that the delinquents will score higher on all the four dimensions of Eysenck personality scale as compared to non delinquents. Findings of the study confirmed the said hypothesis. It was proved that delinquents have higher scores of psychoticism, neuroticism, extraversion, and lie as compared to non-delinquents. The findings of this study can help the parents, teachers, and the law departments to focus on the construction of healthy personality so that the rate of crimes among adolescents can be minimized.
\end{abstract}

\section{Keywords}

Delinquents, Psychoticism, Neuroticism, Extaversion

\section{Introduction}

Juvenile delinquency is an issue which is given great importance by researchers over many years. Comparison between the personality dimensions of delinquents and non delinquents has always been given great attention by personality theorists. Many Psychologists believed that criminal behavior must be explained by personality dimensions of criminals. Both classical and recent researches show that some individuals are crime prone i-e they have certain specific personality features which cause them to involve in illegal activities [1] Developmental psychologists are of the view that adolescence is a stage in which anti-social acts are on peak [2]. Adolescents are on greater risk of committing crimes as compare to adults [3].

Many researchers compare the delinquents and non delinquents on a number of psychological factors. Most but not all studies found the relationship between crime and personality [4]. Most of the researchers compared 
delinquents and non delinquents on the four dimensions of personality given by Eysenck. Almost all the studies showed that delinquents scored higher on psychoticism, neuroticism, extraversion and lie as compared to non-delinquents [5]-[10] compared the inmates with non-inmates and concluded that both differ in their personalities.

This research is an attempt to compare the delinquents and non delinquents on personality dimensions. Juvenile delinquency is one of the most serious problems confronting Pakistan today. The total population of Pakis$\tan$ is 165 million of which $49 \%$ are under the age of 18 years, and most of these adolescents are breaking laws.

The research on the personality dimensions of delinquents is important and useful for both the crime prevention and the treatment of delinquents. This type of research helps to treat the personality disorders in delinquents by knowing their personality features and to help them to avoid anti social acts. The high scores on psychoticism, neuroticism and extroversion will show the need for counseling.

\subsection{Objectives}

The main objectives of the study are as follows:

- To compare the personality dimensions of delinquents and non delinquents.

- To find out the gender differences in the personality dimensions of delinquents.

\subsection{Hypotheses}

The hypotheses of present study are given below:

1) Delinquents will score high on psychoticism as compare to non Delinquents.

2) Delinquents will score high on neuroticism as compare to non Delinquents.

3) Delinquents will score high on extraversion as compare to non Delinquents.

4) Delinquents will score high on lie as compare to non Delinquents.

\section{Research Methodology}

\subsection{Sample Selection}

400 adolescents with the age range of $14-20$ participated in this study. The convenient sampling was used to select the sample which was divided into four categories i-e male delinquents $(\mathrm{n}=100)$, female delinquents $(\mathrm{n}=$ $100)$, male non delinquents $(n=100)$ and female non delinquents $(n=100)$. The delinquents were selected from different jails of Khyber Pukhtunkhwa (Mansehra jail, Abbottabad jail, Haripur jail and Peshawar jail) and non delinquents from different colleges of same districts.

\subsection{Instrument}

The Eysenck Personality Questionnaire (Junior) (Urdu Version 2007) was used in the study. It was originally developed by Eysenck and Eysenck (1970). It was translated and adapted by Naqvi and Kamal in 2007 for measuring the personality dimensions of Pakistani adolescents. It is 81 items scale with dichotomous response options (yes or no) that was develop to measure three dimensions of personality which are extraversion, psychoticism and neuroticism with lie scale. The alpha reliability coefficient of EPQ (junior) for the current study is 0.9 which reveals that it is a reliable instrument to measure personality traits in Pakistani culture.

\subsection{Procedure}

For conducting the present research, the permission letter was signed by supervisor. Then the I.G officers of district Abbottabad, Mansehra, Haripur and Peshawar were approached in their respective offices for taking written approval to visit jail. After taking the permission delinquents were approached in Abbottabad jail, Haripur jail, Mansehra jail and Peshawar central jail of Khyber Pukhtunkhwa. Delinquents were given the brief introduction regarding the objectives of the present study. After developing rapport with the delinquents demographic sheet was filled which consisted of few information like age, sex, socioeconomic status, crime type etc. Then Eysenck Personality Questionnaire Junior was filled from delinquents. The non delinquents were approached from different colleges of Abbottabad, Haripur, Mansehra and Peshawar. After taking permission from the head of the each college the test was administered on them in the same way as on delinquents. The respondents were asked 
to complete the questionnaire honestly. So, in order to find the comparison between delinquents and non delinquents and to find the gender differences, the final data was analyzed by using the t-test.

\section{Results}

Table 1 shows the mean, S.D \& t-value of delinquents and non delinquents on Eysenck personality questionnaire (junior) (Urdu Version 2007) and its subscales. Results indicate that there is significant mean difference (p $<0.000$ ) among delinquents and non delinquents on Eysenck scale and the sub scales of psychoticism, neuroticism, extraversion, and lie scale which shows that delinquents have more tendency of psychoticism, neuroticism, extraversion and lie.

\section{Discussion}

The current study was conducted to find out the differences between the personality dimensions of delinquents and non delinquents. The results of this study indicate that there is a significant difference $(t=20.79, \mathrm{df}=387$, $\mathrm{p}>0.05$ ) between delinquents and non delinquents on the Eysenck Personality Questionnaire (Junior) (Urdu 2007) suggesting that delinquents have higher tendency of psychoticism $(t=11.19)$, extraversion $(t=13.10)$, neuroticism $(t=17.05)$, and lie $(t=13.12)$ than non delinquents. All the four hypotheses are confirmed by the findings.

The results of this study are consistent with the previous researches. Tenibiaji (2010) conducted a comparative study with 121 inmates and 79 non-inmates. By using the Eysenck personality questionnaire it was concluded that inmates and non-inmates differed significantly i-e in-mates scored higher than non-inmates on psychoticism dimension of personality.

Miller and Laynum (2010) by applying five factor model of personality on delinquents concluded that anti social individuals are high on neuroticism dimension of the personality. In another study Jie along with his colleagues (2009) compared the 378 juvenile delinquents with 410 students of high school by using the Askenk's character questionnaire. The results showed that juvenile delinquents scored higher on extroversion scale as compared to high school students. Moreover it was shown that there is positive correlation between the scores on lie scale and the scores on delinquency, i-e the higher scores on lie scale is linked with delinquency.

\section{Implications of the Study}

This study focused on the relationship between the personality dimensions and delinquency. The obtained findings can be helpful for psychologists, parents, social workers, teachers, jail staff, and the authorities of other institutions working for the mental health of delinquents to control the crime rate and to develop the prevention programs for delinquents.

Findings of this study suggest that personality dimensions (psychoticism, neuroticism, extraversion and lie) should be included and used in criminological models for development of intervention strategies of delinquents.

\section{Acknowledgements}

I strongly acknowledge the kind guidance of Professor Doctor Maher Bano throughout the research and the fi-

Table 1. Mean, standard deviation, and t value of delinquents and non delinquents on eysenck personality scale and its sub scales.

\begin{tabular}{|c|c|c|c|c|c|c|}
\hline & \multicolumn{6}{|c|}{ Group } \\
\hline & \multicolumn{2}{|c|}{ Delinquents $(n=200)$} & \multicolumn{2}{|c|}{ Non-delinquents $(\mathrm{n}=200)$} & \multirow[t]{2}{*}{$\mathrm{t}$} & \multirow[t]{2}{*}{$\mathrm{p}$} \\
\hline & M & SD & M & SD & & \\
\hline Eysenck & 54.9 & 11.59 & 34.2 & 7.36 & 20.7 & 0.000 \\
\hline Psychoticism & 8.47 & 4.85 & 4.08 & 2.69 & 11.19 & 0.000 \\
\hline Neuroticism & 14.87 & 4.11 & 7.83 & 4.15 & 17.055 & 0.000 \\
\hline Extraversion & 16.85 & 4.04 & 11.57 & 4.02 & 13.104 & 0.000 \\
\hline Lie & 14.70 & 3.39 & 9.99 & 3.77 & 13.12 & 0.000 \\
\hline
\end{tabular}

df $=398 / 397 ; p>0.05$. 
nancial support from Association of commonwealth universities.

\section{References}

[1] Hampson, E.S. and Kline, P. (1977) Personality Dimensions Differentiating Certain Groups of Abnormal Offenders from Non-Offenders. The British Journal of Criminology, 17, 310-333.

http://bjc.oxfordjournals.org/content/17/4/310.full.pdf

[2] Bacon, S., Paternoster, R. and Brame, R. (2008) Understanding the Relationship between Onset Age and Subsequent Offending during Adolescence. Journal of Youth and Adolescence, 38, 301-311. http://dx.doi.org/10.1007/s10964-008-9322-7

[3] Cobb, J.N. (2003) Adolescence, Continuity, Change, and Diversity. 4th Edition, Mayfield Publishing Company, USA.

[4] Cale, E.M. (2006) A Quantitative Review of the Relations between the "Big 3" Higher Orders Personality Dimension and Anti Social Behavior. Journal of Research in Personality, 40, 250-284. http://dx.doi.org/10.1016/j.jrp.2005.01.001

[5] Ardalan, D., Iravani, M. and Sobhi-Gharamaleki, N. (2010) A Comparison of the Personality Characteristics of Delinquent and Non-Delinquent Juveniles of Tehran, Iran. International Journal of Criminology and Sociological Theory, $\mathbf{3}$, 372-384. http://pi.library.yorku.ca/ojs/index.php/ijcst/article/view/26083

[6] Dunlop, D.P., Morrison, L.D., Koenig, J. and Silcox, B. (2010) Comparing the Eysenck and HEXACO Models of Personality in the Prediction of Adult Delinquency. European Journal of Personality, 25.

[7] Corf, L.Y. and Toupin, J. (2009) Comparing Persistent Juvenile Delinquents and Normative Peers with the Five Factor Model. Journal of Research in Personality, 43, 1105-1108. http://dx.doi.org/10.1016/j.jrp.2009.06.011

[8] Herzberg, Y.P. and Hoyer, J. (2009) Personality Prototypes in Adult Offenders. Criminal Justice Behavior, 36, 259274. http://dx.doi.org/10.1177/0093854808328331

[9] Monahan, K.C., Laurance, S., Elizbeth, C. and Edward, M. (2009) Trajectories of Antisocial Behavior and Psychosocial Maturity from Adolescence to Young Adulthood. Developmental Psychology, 45, 1654-1668. http://dx.doi.org/10.1037/a0015862

[10] Heaven, L.C.P. and Virgen, M. (2001) Personality, Perception of Family and Peer Influences, and Males Self Reported Delinquency. Personality and Individual and Differences, 30, 321-333.

http://dx.doi.org/10.1016/S0191-8869(00)00049-0 